\title{
Denplan comes of age - a personal view
}

\author{
P. B. F. Swiss
}

IN BRIEF

- When Denplan was started in 1987, only about $7 \%$ of dentistry in the UK was being provided privately.

- After slow initial growth by 1994 there were 500,000 registered patients, one million by 2002 , and about 1.8 million patients at the present time.

- Is capitation an acceptable alternative to fee-per-item as a system for the provision for regular dental care?

Dental plans are a relatively recent addition to the profession and although there are now a number of options for practitioners to consider, Denplan was the pioneer in the 1980s. Celebrating its $21^{\text {st }}$ birthday this year, Peter Swiss a former Dental Director of the company, reflects on its pioneering beginnings, its development and the place of capitation plans in dentistry.

It would perhaps be appropriate, in view of the continuing debate about the current NHS dental contract and the relationship between NHS and private dental care, to reflect on the introduction of Denplan 21 years ago and its subsequent development.

It was in the mid 1980s, whilst working with me at the Medical Defence Union, that Stephen Noar and Marilyn Orcharton met and devised the idea of a private capitation scheme. After very considerable planning and development, and also at very considerable personal financial risk, the concept of Denplan was introduced to the profession in November 1986 in Winchester, prior to it 'going live' in January 1987. However, very disappointingly, the launch was attended by less than 30 people, with only a handful of practices showing any significant interest.

The concept was, in essence, that the dentist would provide all necessary regular dental care for a patient for a monthly private fee, this fee being set by the dentist following an initial clinical assessment. The clinical contract was thus between the patient and an individual dentist. Denplan would collect the patient's monthly fees and would deduct an administration charge before sending the balance to the dentist; this charge would include an insurance element to meet the private cost of out-ofhours emergency cover and treatment for dental trauma. Thus patients would receive their regular dental maintenance care through Denplan for a previously agreed monthly fee, with insurance to cover unexpected costs. Furthermore, any dentist treating patients under Denplan Care was required to sign a contract with Denplan agreeing to abide by certain professional requirements.

At that time this was a very radical concept. Dentistry in the UK was almost entirely provided under the NHS on a fee per item basis, with only about 7\% of dentistry being provided privately. The concept of a private capitation scheme was thus something entirely new and, perhaps not surprisingly, was viewed by many dentists with scepticism and by others as being irrelevant to their busy NHS practices. To a profession accustomed to providing dental treatment under a fee per item NHS payment system, the concept of a capitation system of remuneration was an alien one and especially one where it was for individual dentists to set their own fees.

So perhaps not surprisingly, and despite the very considerable advertising and marketing undertaken by Denplan at the time, the take-up of this new private dental care scheme was initially very slow, such that its future long-term viability was far from certain. However, it was not long before help came from an unexpected source. The introduction of the 'new' NHS contract in 1990, followed by the 7\% claw back in 1992, caused considerable professional resentment and resulted in many dentists deciding that they would no longer continue to treat patients exclusively on the NHS 'treadmill' and led many to consider other options. Many dental practices decided to move significantly into the private sector and the predictable cost of treatment under Denplan Care was a more attractive option for many patients than the unpredictable cost of 'pay as you go' private treatment. A second piece of good fortune for Denplan was that, probably because of its inauspicious start and the early professional scepticism, for many years no major competitors entered the market and so Denplan was, at least, well placed to attract those practices and patients seeking a predictable private alternative to NHS dental care.

But it was not just a matter of good fortune. From its inception, the Directors were very aware that Denplan would only be accepted and become established if it was seen to have a sound clinical and professional ethos and was 'run by dentists for dentists'. To that end, both an Advisory Board comprising about a dozen leading members of the dental profession and also a peer review programme were established during the first year. Further professional 
initiatives, including the introduction of a practice quality programme, postgraduate courses and the first private dental complaints service all followed, and throughout the past 21 years Denplan has devoted significant time and effort in developing its professional services for dentists.

So, after slow initial growth for the first few years, the move away from NHS dental practice from 1992 onwards resulted in a rapid increase in both dentists and patients opting for private dental care, with Denplan attracting a significant proportion. By 1994 there were 500,000 registered patients, one million by 2002, and about 1.8 million patients at the present time receive their regular dental care from about 7000 dentists under Denplan care.

So, has it been a success story and is capitation an acceptable alternative to fee-per-item as a system for the provision for regular dental care? It has been suggested that such a system might encourage supervised neglect, whereas a fee-per-item system might encourage over-prescription. In my view this is an over-simplification as neither system is inherently unsatisfactory or unethical. As long as both the contractual requirements and the levels of remuneration are acceptable, with the latter preferably being set by the dentist rather than by a third party, dentists will be able to provide appropriate and ethical dental care for their patients under whichever system they choose to work.

The introduction of Denplan care 21 years ago provided an option for general dental practitioners wishing to reduce their reliance on the NHS and for those patients wishing to receive private treatment. However it has never, in my view, been suitable for all patients. Firstly, because it is a system suitable for the provision of routine dental care for the regularly attending patient; secondly, for those patients who are content to pay privately for their dental care as and when required, conventional private dental care would seem the obvious choice. However, for patients who wish to have their regular dental care provided on a private basis, and at a predetermined cost, then a capitation plan may well be a more attractive option.

Whilst the huge increase in private dental care since 1987 has been largely led by a profession seeking an alternative to NHS dentistry, increasing numbers of patients also continue to place greater importance on their dental care and expect private dentistry to offer this. Denplan should be congratulated on the introduction of an alternative system for the provision of private dental care which, during the past 21 years, has proved to be increasingly popular with both patients and dentists.

Peter Swiss was Dental Director of Denplan 1994-97 and retired as Chairman of the Denplan Advisory Board in 2000. He was President of the British Dental Association in 2001-02. peterswiss@btinternet.com

\section{Erratum}

CPD questions (BDJ 2008; 205: 338)

It has been brought to our attention that in $B D J$ volume 205 issue 6, CPD Article 1 question 2 read as follows:

2. What percentage of people with rheumatoid arthritis have iron deficiency anaemia?

A. $23 \%$

B. $77 \%$

C. $33 \%$

D. $33-60 \%$

Option A should have read '23\% of 33-60\%'. This was the correct answer.

A notice was posted on the Eastman CPD website as soon as the error came to our attention.

We apologise for any inconvenience caused. 